\title{
Effect of Annealing Atmosphere Induced Crystallite Size Changes on the Electrochemical Properties of $\mathrm{TiO}_{2}$ Nanotubes Arrays
}

\author{
Tauseef Anwar ${ }^{1}$, Wang $\mathrm{Li}^{1}$, Naveed Hussain ${ }^{1}$, Wang $\mathrm{Chen}^{1}$, Rizwan Ur Rehman Sagar ${ }^{2}$ and Liang Tongxiang ${ }^{3}$ \\ 1. Beijing Key Lab of Fine Ceramics, Institute of Nuclear and New Energy Technology, Tsinghua University, Beijing 100084, China \\ 2. Nanshan District Key Lab for Biopolymers and Safety Evaluation, College of Materials Science and Engineering, Shenzhen \\ University, Shenzhen 518060, China \\ 3. State Key Lab of New Ceramic and Fine Processing, Tsinghua University, Beijing 100084, China
}

\begin{abstract}
TNAs (Titanium dioxide nanotube arrays) were synthesized by electrochemical anodization and these TNAs were annealed in different gas atmosphere such as argon, air, hydrogen and nitrogen. This annealing in different atmosphere brought variation in crystallite size $\left(27 \sim 33 \mathrm{~nm}\right.$ ), which influences on electrochemical properties. The specific capacity of Ar, Air, $\mathrm{N}_{2}$ and $\mathrm{H}_{2}$-annealed TNAs was around $\sim 165,185,177$ and $190 \mathrm{mAh} \mathrm{g}^{-1}$, respectively. The crystallite size of anatase TNAs seemed to be responsible for the change in lithium storage capacity, indicating that structural changes of TNAs were playing major role in electrochemical properties.
\end{abstract}

Key words: LIB (Lithium Ion Battery), electrochemical properties, crystallite size, TNAs.

\section{Introduction}

The development of high energy and power density LIBs (lithium-ion batteries) is very important due to the increasing demand of the energy conversion and storage devices for digital appliances and other portable electronic products. Electrode materials play a key role in electrochemical lithium storage of LIBs, which essentially affect battery performance such as the voltage, charge/discharge capacity, rate ability, and cycle stability. As for the anode materials, the traditional commercial graphite anode material has not only almost reached their theoretical capacity (372 $\mathrm{mAh}^{-1}$ ) [1], but also suffered from issues such as irreversible capacity loss, and high reactivity with electrolyte solution that creates safety issue [2]. Therefore, developing novel anodes with higher capacity and superior stability has become an urgent task. Nanomaterials of metal oxides, such as $\mathrm{Co}_{3} \mathrm{O}_{4}[3$,

\footnotetext{
Corresponding author: Liang Tongxiang, Ph.D., professor, research field: ceramic materials. E-mail: txliang@tsinghua.edu.cn.
}

4], $\mathrm{SnO}_{2}$ [5], $\mathrm{FeO}_{\mathrm{x}}[6], \mathrm{V}_{2} \mathrm{O}_{5}$ [7] and $\mathrm{NiO}$ [3] have been intensively studied as anode materials for LIBs aimed at achieving higher specific capacities than graphite. For instance, nanocrystals of $\mathrm{Co}_{3} \mathrm{O}_{4}$ have been synthesized for LIBs anodes with specific capacities $\sim 2$ times that of graphite, affording LIBs with higher energy density $[3,8]$. In these oxide materials, titanium dioxide $\left(\mathrm{TiO}_{2}\right)$ have comparable equitant graphitic specific capacity $335 \mathrm{mAh} \quad \mathrm{g}^{-1}$ but several advantageous properties, such as higher working voltage window, low volume expansion (3\%) to ensure long cycling life, low toxicity, environmental benignity, widespread availability. The excellent safety operation and high power density can be expected from $\mathrm{TiO}_{2}$ anodes and considered an attractive anode candidate for LIBs $[9,10]$.

Amongst the various nano-structures of $\mathrm{TiO}_{2}$ employed for LIBs application [11-16], titanium dioxide nanotube arrays (TNAs) $[17,18]$ are favorable nanomaterial for lithium ion storage due to high specific surface area, high porosity, vertical orientation, 
etc $[16,17,19]$. The synthesis and transformation of material properties in different gaseous atmosphere is already well established technique [20,21]. Hansen et al. [22] studied the dynamic reversible shape changes in nanocrystals in different gaseous environment. Jian et al. [23, 24] synthesized high purity $\mathrm{Cu}$ nanoparticle by gas induced formation. Annealing of TNAs, depending upon the annealing temperature [25, 26], pressure [27] and gaseous atmosphere [28, 29] can significantly alter their specific capacities. Annealing is believed to induce structural changes in TNAs which are responsible for changes in specific capacities. For example, Lui et al. reported specific capacity of 223 $\mathrm{mAh} \mathrm{g}^{-1}$ and $164 \mathrm{mAh} \mathrm{g}^{-1}$ of the TNAs annealed in the environment of $\mathrm{CO}$ and $\mathrm{N}_{2}$, respectively [29]. Annealing not only can improve the performance of LIBs but can also potentially act as an important tool to tailor their performance. Rai et al. [26] annealed titania at different temperature $\left(300 \sim 600{ }^{\circ} \mathrm{C}\right)$ and correlated the effect of temperature induced changes with electrochemical properties. Though, there are several reports about the changes in $\mathrm{Ti}^{+3}$ concentration, oxygen vacancies, defects and change in size of titania after annealing at different temperatures and different gases $[25,26,28-32]$ but to best of our knowledge, there are no detail reports about changes in crystallite size of TNAs annealed in different gaseous atmospheres and its correlation with the specific capacity.

Herein, we report the synthesis of TNAs by electrochemical anodization and effect of annealing in different gaseous atmosphere on their crystallite size and specific capacity. The specific capacity of TNAs annealed under atmosphere of $\mathrm{Ar}$, Air, $\mathrm{N}_{2}$ and $\mathrm{H}_{2}$ was 165, 185, 177 and $190 \mathrm{mAh} \mathrm{g}^{-1}$, respectively. Annealing induced structural changes in TNAs (vacancies, defects etc.) may have influenced their crystallite size and ultimately their electrochemical properties. This annealing induced variation in crystallite size may prove helpful to achieve tunable electrochemical properties of TNAs based high performance LIBs. Therefore, this method is proved to be a general and facile technique to improve the power density of $\mathrm{TiO}_{2}$ anode materials for lithium-ion batteries.

\section{Experimental Details}

\subsection{Synthesis of Titanium Dioxide Nanotube Arrays}

The TNAs were fabricated by anodization of titanium foil. The preparation of TNAs was explained in our previous work [33, 34]. After preparing TNAs, voltage is increased swiftly to $110 \mathrm{~V}$ for five minutes to peel out nanotubes for further use in lithium-ion half-cell. The TNAs peeled out automatically or a little mechanical stress is required after drying at room temperature. The peeled out nanotubes are dried overnight at $105^{\circ} \mathrm{C}$ and annealed at $450{ }^{\circ} \mathrm{C}$ for $2 \mathrm{~h}$ in different atmosphere, including oxygen rich air, inert gas $\mathrm{Ar}$ and reductive gases of $\mathrm{N}_{2}$ and $\mathrm{H}_{2}\left(\mathrm{Ar} 95 \%+\mathrm{H}_{2}\right.$ $5 \%$ mixture). After the annealing treatment, the TNAs transform from amorphous to anatase.

\subsection{Characterization}

The surface and cross-sectional morphologies of the TNAs were characterized using Field Emission Scanning Electron Microscopy (FE-SEM LEO 1530). The average nanotube dimensions were also determined by using SEM. The phase purity of TNAs annealed in different atmosphere was characterized by using X-ray powder diffraction (XRD). The $\mathrm{Cu} \mathrm{K \alpha}$ radiation with wavelength $\lambda=0.154 \mathrm{~nm}$ were used for XRD analysis.

\subsection{Electrochemical Characterization}

The lithium storage performances of TNAs were evaluated using Li|TNAs half-cells. The cells were 2032 coin cell and assembled in argon filled glove box. The electrode was a mixture of the TNAs:conductive-carbon:binder with a ratio of 70:24:6, respectively. A celgard 2300 polypropylene separator soaked with a liquid electrolyte of $1 \mathrm{M} \mathrm{LiPF}_{6}$ dissolved in a 1:1 volume ratio of EC (ethylene carbonate) and DMC (dimethyl carbonate) was placed 

on the Electrochemical Properties of $\mathrm{TiO}_{2}$ Nanotubes Arrays

between the electrodes. The cells were galvanostatically charged and discharged between 1.0 and $2.5 \mathrm{~V}\left(\mathrm{vs} . \mathrm{Li}^{+} / \mathrm{Li}\right)$ at $0.1 \mathrm{C}$-rate.

\section{Results and Discussion}

The morphology and surface analysis of the TNAs annealed in different atmosphere were observed by using SEM (Figs. 1a-1d). The open ends of TNAs could be observed from the top view of SEM images. The cross-sectional view showed columnar-stacked TNAs which was an identification of tube like morphology. The inner diameter of these TNAs was about 40 to $60 \mathrm{~nm}$. The nanotubes of $\mathrm{TiO}_{2}$ were grown vertically from bottom to top with the length of 10 to 15 $\mu \mathrm{m}$. The TNAs annealed in different atmosphere have no specific change in morphology with respect to each other which is consistent with previous reported literature [20,35]. It showed that annealing atmosphere did not affect the shape and size of TNAs under different atmosphere (Fig. 1).

The as-prepared TNAs did not show peaks in its XRD pattern, indicating that it was amorphous (Fig. 2). The XRD pattern of annealed TNAs in Ar, Air, $\mathrm{N}_{2}$ and $\mathrm{H}_{2}$ can be indexed to anatase $\mathrm{TiO}_{2}$ (JCPDS 21-1272). The amorphous as-prepared TNAs transformed into a polycrystalline tetragonal anatase structure, regardless of annealing atmospheres annealed at $450{ }^{\circ} \mathrm{C}$ for $2 \mathrm{~h}$ [33]. The rutile phase was not observed in these TNAs, suggested the presence of anatase phase alone. Though TNAs annealed in different atmosphere were anatase, but they showed different shifts in peak position, which can be observed by comparison of (200) diffraction peaks (inset of Fig. 2). Generally, the shift in the peak position represents the change in degree of disorder in the material. The peak shift here might be attributed to change in crystal parameters or crystallite size, which is caused by distortion of lattice parameters by annealing in different atmosphere. So, the structural
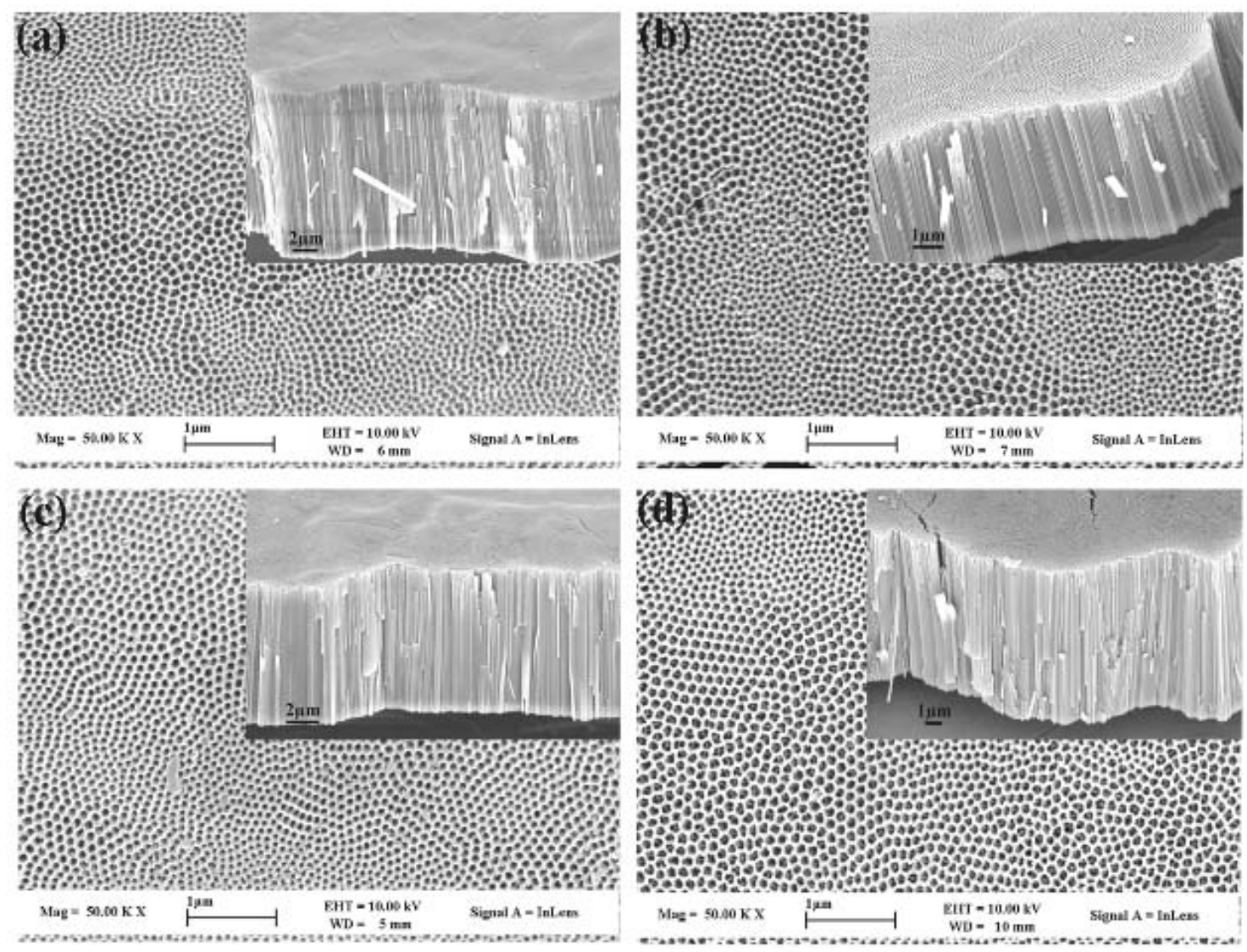

Fig. 1 The surface and lateral views (inset) of the TNAs annealed in different atmosphere of (a) $\operatorname{Ar}$ (b) $\operatorname{Air}$ (c) $\mathrm{N}_{2}$ (d) $\mathrm{H}_{2}$. 


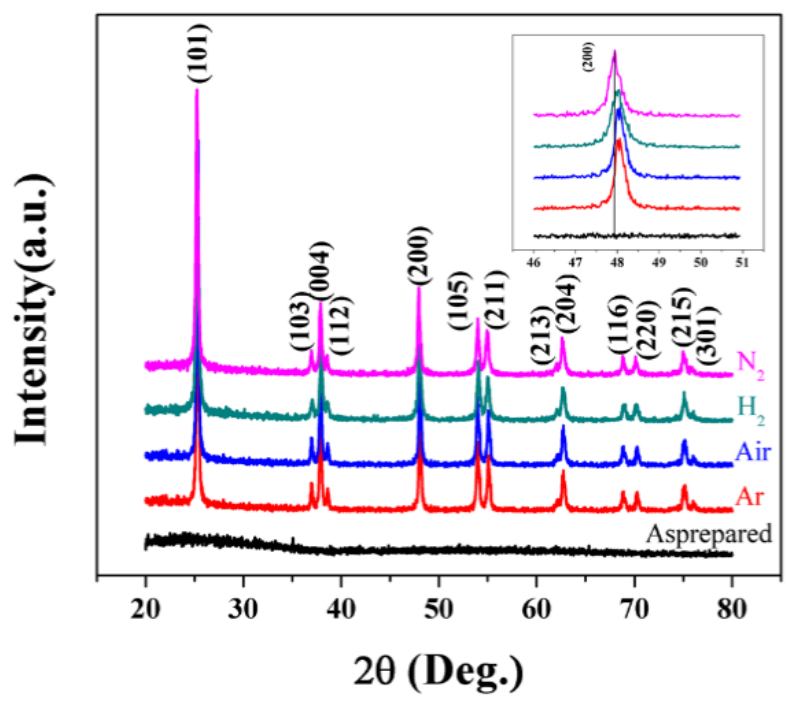

Fig. 2 XRD patterns of TNAs annealed in different atmosphere (inset shift in (200) peak).

defects such as change in crystallite size and grain boundaries, oxygen vacancies, $\mathrm{Ti}^{+4} / \mathrm{Ti}^{+3}$ ratio introduced by annealing TNAs in different atmosphere were obviously different [36].

The electrochemical insertion and extraction of $\mathrm{Li}$ was completed by the accumulation of electrons in $\mathrm{TiO}_{2}$ electrodes in contact with $\mathrm{Li}^{+}$containing electrolytes according to following reaction $[37,38]$ :

$$
\mathrm{TiO}_{2}+x \mathrm{Li}^{+}+x e^{-} \leftrightarrow \mathrm{Li}_{x} \mathrm{TiO}_{2}
$$

As the anatase $\mathrm{TiO}_{2}$ have a series of octahedral and tetrahedral vacant sites which accommodate lithium up take of $0.5 \mathrm{Li}$ per formula unit, corresponding to a theoretical capacity of $168 \mathrm{mAh} \mathrm{g}^{-1}$ [39]. The lithium insertion into anatase $\mathrm{TiO}_{2}$ is two phase mechanism in Li-poor tetragonal and Li-rich orthorhombic phase (structural distortion phase) [37]. The TNAs annealed in different atmospheres showed potential plateau around $1.75 \mathrm{~V}$ during the discharge and $1.95 \mathrm{~V}$ during the charge, though the value changed with annealing atmosphere (Fig. 2a). The two potential plateaus can be observed in discharge curve is attributed to $\mathrm{Li}^{+}$ insertion/extraction from interstitial and octahedral sites of TNAs. The discharge capacity of the 2 nd cycle at the $0.1 \mathrm{C}$-rate for $\mathrm{Ar}$, Air, $\mathrm{N}_{2}$ and $\mathrm{H}_{2}$-annealed samples was around 165, 185, 177 and $190 \mathrm{mAh} \mathrm{g}^{-1}$, respectively (Fig. 3a). So the specific capacity for
TNAs annealed in all samples is different and can be tuned by annealing in different atmosphere due to inducing structural changes.

The TNAs annealed in different atmosphere showed different cycle stability (Fig. 3b). Annealing in different atmosphere results in different capacity fading. For example, Ar, Air and $\mathrm{N}_{2} / \mathrm{H}_{2}$-annealed samples have capacity fading rate $1.126 \%, 0.5786 \%$, $1.3 \%$ and $1.9 \%$, respectively. Moreover, the capacity retention of $66 \%, 82 \%, 61 \%$ and $41 \%$ was obtained after 30 cycles for $\mathrm{Ar}$, Air, $\mathrm{N}_{2}$ and $\mathrm{H}_{2}$-annealed samples, respectively. The TNAs annealed in oxidic atmosphere showed higher capacity retention than that of annealed in reductive atmosphere because of better crystallinity in oxygen annealed TNAs as compared to reductive atmosphere annealed TNAs.

The rate performance of TNAs annealed in different atmosphere was investigated at the $\mathrm{C}$ rate of $\mathrm{C} / 4, \mathrm{C} / 2$, C, $5 \mathrm{C} / 4,5 \mathrm{C}$ and $\mathrm{C} / 4$ (Fig. $3 \mathrm{c}$ ). The rate performance was better for TNAs annealed in Air and $\mathrm{N}_{2}$ for most of $\mathrm{C}$ rates except for $5 \mathrm{C}$. The rate performance for $\mathrm{H}_{2}$-annealed sample was the lowest for all $\mathrm{C}$ rates except at $5 \mathrm{C}$ and rate performance for Ar-annealed among $\mathrm{H}_{2}$ and $\mathrm{N}_{2}$-annealed sample.

Although, $\mathrm{H}_{2}$-annealed sample presents higher specific capacity as compared to Air-annealed sample, its cyclic and rate performance were worse. Similarly, the cyclic and rate performance Ar-annealed were close to Air-annealed TNAs, but its specific capacity is the lowest. The specific capacity and rate performance of $\mathrm{N}_{2}$ annealed sample were better than Ar-annealed, which attributed to the reduction of charge transfer resistance of $\mathrm{N}_{2}$ annealed atmosphere while cyclic performance is similar to Ar-annealed TNAs [40]. So the comparative study on the electrochemical properties of TNAs annealed in different atmosphere revealed that enhancement of specific capacity might be obtained.

The effect of annealing atmosphere on the lithium storage performances of TNAs could be related with the change in the crystallite size. The size of crystallite 

on the Electrochemical Properties of $\mathrm{TiO}_{2}$ Nanotubes Arrays
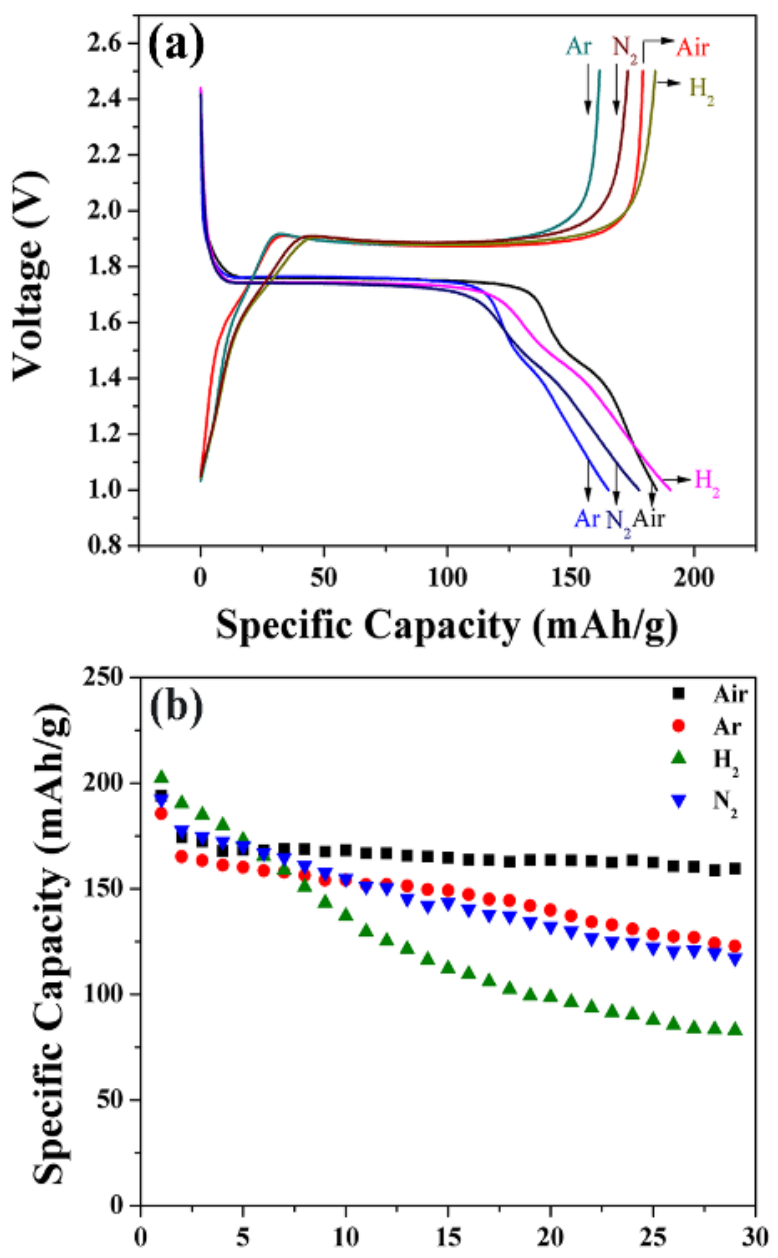

Cycle Number

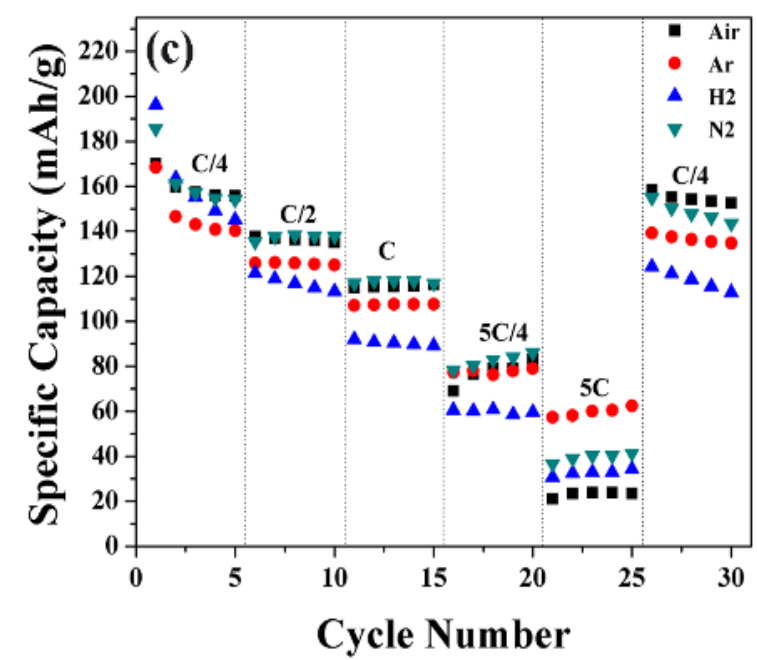

Fig. 3 (a) Charge/discharge curve of 2 nd cycle for TNAs annealed in different atmosphere at the potential of $1 \mathrm{~V}$ to $2.5 \mathrm{~V}$. (b) Discharge capacity in all annealing atmosphere samples versus cycle number at the rate of $0.1 \mathrm{C}$. (c) Rate capacity of the arrays as a function of the cycle number at different $\mathrm{C}$ rates. may be varied during the annealing in different atmosphere, as a result charge transfer properties and crystal stability may be changed accordingly. Therefore, difference in crystallite size of material may cause difference in the lithium storage performances (Fig. 4). Reddy et al. [41] grew $\mathrm{TiO}_{2}$ brookite phase and studied the effect of crystallite size at lithium insertion. According to their study, lithium insertion decreases as the crystallite size increases and vice versa. The increase in lithium insertion in smaller crystallite size is attributed to decrease in lithium diffusion path length. The effect of annealing atmosphere on the lithium storage performances of TNAs could be related with the change in the structure. The unit cell parameters and crystallite size may be varied during the annealing in different atmosphere, as a result charge transfer properties and crystal stability may be changed accordingly. The unit cell lattice parameters were calculated by using a least-squares Bragg peak fitting method for anatase (101) Bragg reflection peak. The lattice parameters show no noticeable change along a and $\mathrm{b}$ directions, but obvious change along the $\mathrm{c}$ direction from $8.9096 \AA$ to $9.4981 \AA$ upon annealing in different atmosphere (Table 1).

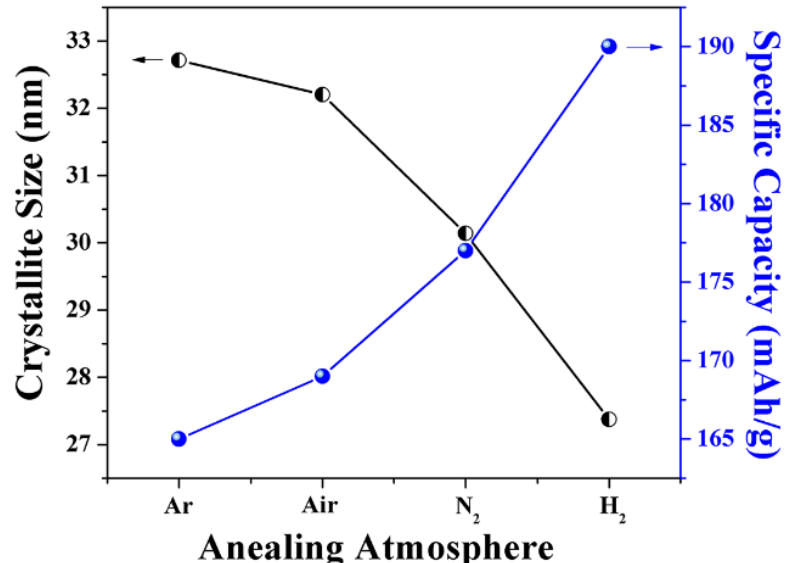

Fig. 4 Variation of crystallite size and specific capacity with annealing atmosphere.

Table 1 The unit cell parameters of TNAs annealed in different atmosphere.

\begin{tabular}{llllll}
\hline Para. & Stand. [43] & $\mathrm{Ar}$ & $\mathrm{Air}$ & $\mathrm{N}_{2}$ & $\mathrm{H}_{2}$ \\
\hline $\mathrm{a} / \AA$ & 3.7845 & 3.7806 & 3.7815 & 3.7810 & 3.7887 \\
$\mathrm{c} / \AA$ & 9.5143 & 8.9096 & 9.4981 & 8.9530 & 9.3643 \\
\hline
\end{tabular}


Obviously this change in unit cell parameters alter crystallite size. Therefore, difference in crystallite size of material may cause difference in the lithium storage performances (Fig. 4). The crystallite size estimated via Scherrer formula [42].

$$
\text { Crystallite Size }=K \frac{\lambda}{\beta \cos \theta}
$$

where $\lambda$ is wavelength of $X$-ray, $\beta$ is the peak width of the diffraction peak at half maximum height and $K$ is a constant related to crystallite shape. The crystallite size was evaluated by using the main anatase X-ray diffraction peak (101) and it was in the range of 33-27 nm. The crystallite size of Ar-annealed sample was the largest, while decreased for the samples annealed in Air, $\mathrm{N}_{2}$ and $\mathrm{H}_{2}$, respectively. The smallest crystallite size was observed for the $\mathrm{H}_{2}$-annealed TNAs sample. Hosseinpour et al. [44, 45] studied the annealing effect in different atmosphere and depicted that as lattice parameters altered the crystallite size also follow trend which is according to our observations.

The specific capacity of TNAs annealed in different atmosphere was co-related with crystallite size (Fig. 4). The crystalite size decreased and specific capacity increased expotentially with respect to the annealing atmosphere from $\mathrm{Ar}$ to $\mathrm{H}_{2}$. The specific capacity was tuned from 165-195 $\mathrm{mAh} \mathrm{g}^{-1}$ depending upon annealing atmosphere. The decrease in crystallite size allowed rapid lithium-ion intercalation and deintercalation due to the short distances for lithium-ion transport. The characteristic time constant for diffusion is $\mathrm{t}=\mathrm{L}^{2} / \mathrm{D}$, where $\mathrm{L}$ is the diffusion length and $\mathrm{D}$ the diffusion constant. So as the time for intercalation decreases with reduction of crystallite size which may be a reason for increasing specific capacity. Liu et al. [19] described that structure disorder TNAs have higher capacity due to the higher degree of defects that enhance intercalation of lithium ions.

The TNAs annealed in different atmosphere have different crystallite size. The highest specific capacity was observed for $\mathrm{H}_{2}$-annealed TNAs, while it has the lowest crystallite size. On the other hand, Ar-annealed sample have highest crystallite size yet lowest specific capacity because reduction in crystallite size is minimum, so its electrochemical properties were comparable to Air-annealed nanotubes. For the Air-annealed sample, the oxygen rich environment could lower down its oxygen vacancies as a result reduction in crystallite size is also minute. The specific capacity did not change a lot in comparison to Ar-annealed sample. The doping in TNAs could be possible in $\mathrm{N}_{2}$-annealed sample yet there is not any phase change was observed in XRD pattern. Therefore, doping was out of question. The $\mathrm{N}_{2}$ gas have not very strong reducing behavior so it produced lower oxygen vacancies as compared to $\mathrm{H}_{2}$. The lithium intercalation was less than $\mathrm{H}_{2}$-annealed TNAs but more than Ar-annealed due to their reducing and non-reducing nature, respectively. The nanotubes annealed in Ar (inert gas) and Air (oxygen rich) have larger crystallite sizes, while the TNAs annealed in gases having reductive nature producing small crystallite size lead high specific capacity.

The specific capacity largely depends upon two factors such as the conductivity and intercalation of lithium ions in the material. The intercalation of lithium ions is closely related to crystal defects as the crystal defects increase more and more lithium ions can intercalate, suggesting an increase in specific capacity. On the other hand, conductivity of material decreases with increase of crystal defects, as a result recombination of charges and lithium ions reduces. The reduction into recombination of lithium ions and electrons resulted into less specific capacity but higher intercalation of lithium ions plays the major role in our samples. The highest specific capacity was observed for the lowest crystallite size, indicating higher lithium intercalation is playing major role.

\section{Conclusions}

The TNAs of inner diameter of 40 to $60 \mathrm{~nm}$ and lateral length of 10 to $15 \mu \mathrm{m}$ were synthesized by two-step anodic oxidation. The as-prepared TNAs 
were amorphous and transformed into anatase after annealing in different atmosphere. Annealing in oxygen deficient (Ar) and, oxygen rich (Air) and reducing gases $\left(\mathrm{H}_{2}\right)$ and $\left(\mathrm{N}_{2}\right)$ induced variations in the crystallite size which affect physical properties of TNAs especially electron transport and cation diffusion. Based on the results of effect of annealing on physical properties of TNAs we were able to optimize the specific capacity of lithium ion battery to $190 \mathrm{mAh} \mathrm{g}^{-1}$.

\section{Acknowledgments}

This work is supported by the National Natural Science Foundation of China (Grand No. 21271114); Tsinghua University independent research and development fund (20111080982) and Program for Changjiang Scholars and Innovative Research Team in University (IRT13026).

\section{Reference}

[1] Chen, J. 2013. "Recent Progress in Advanced Materials for Lithium Ion Batteries." Materials 6: 156-83.

[2] Spotnitz, R., and Franklin, J. 2003. "Abuse Behavior of High-Power, Lithium-Ion Cells." J Power Sources 113: 81-100.

[3] Poizot, P., Laruelle, S., Grugeon, S., Dupont, L., and Tarascon, J. M. 2000. "Nano-Sized Transition-Metal Oxides as Negative-Electrode Materials for Lithium-ion Batteries." NATURE 407: 496-9.

[4] Zhao, Y., Chen, S., Sun, B., Su, D., Huang, X., Liu, H., Yan, Y., Sun, K., and Wang, G. 2015. "Graphene- $\mathrm{Co}_{3} \mathrm{O}_{4}$ Nanocomposite as Electrocatalyst with High Performance for Oxygen Evolution Reaction.” Scientific Reports 5.

[5] Li, Y. D., Zhao, S. X., Nan, C. W., and Li, B. H. 2011. "Electrochemical Performance of $\mathrm{SiO}_{2}$-Coated $\mathrm{LiFePO}_{4}$ Cathode Materials for Lithium-Ion Battery." J Alloys Compd 509: 957-60.

[6] Jiao, Y., Han, D., Ding, Y., Zhang, X., Guo, G., Hu, J., Yang, D., and Dong, A. 2015. "Fabrication of Three-Dimensionally Interconnected Nanoparticle Superlattices and their Lithium-Ion Storage Properties." Nat Commun 6.

[7] Liu, Q., Li, Z. F., Liu, Y., Zhang, H., Ren, Y., Sun, C. J., Lu, W., Zhou, Y., Stanciu, L., Stach, E. A., and Xie, J. 2015. "Graphene-Modified Nanostructured Vanadium Pentoxide Hybrids with Extraordinary Electrochemical Performance for Li-Ion Batteries." Nat Commun 6.

[8] Nam, K. T., Kim, D. W., Yoo, P. J., Chiang, C. Y.,
Meethong, N., Hammond, P. T., Chiang, Y. M., and Belcher, A. M. 2006. "Virus-Enabled Synthesis and Assembly of Nanowires for Lithium-Ion Battery Electrodes." Science 312: 885-8.

[9] Qu, J., Cloud, J. E., Yang, Y., Ding, J., and Yuan, N. 2014. "Synthesis of Nanoparticles-Deposited Double-Walled $\mathrm{TiO}_{2}$-B Nanotubes with Enhanced Performance for Lithium-Ion Batteries." ACS Appl Mater Interfaces 6: 22199-208.

[10] Wu, Q. L., Li, J., Deshpande, R. D., Subramanian, N., Rankin, S. E., Yang, F., and Cheng, Y. T. 2012. "Aligned $\mathrm{TiO}_{2}$ Nanotube Arrays as Durable Lithium-Ion Battery Negative Electrodes." J Phys Chem C 116: 18669-77.

[11] Armstrong, G., Armstrong, A. R., Bruce, P. G., Reale, P., and Scrosati, B. 2006. " $\mathrm{TiO}_{2}(\mathrm{~B})$ Nanowires as an Improved Anode Material for Lithium-Ion Batteries Containing $\mathrm{LiFePO}_{4}$ or $\mathrm{LiNi} 0.5 \mathrm{Mn} 1.5 \mathrm{O}_{4}$ Cathodes and a Polymer Electrolyte." Adv Mater 18: 2597-600.

[12] Qiu, Y., Yan, K., Yang, S., Jin, L., Deng, H., and Li, W. 2010. "Synthesis of Size-Tunable Anatase TiO2 Nanospindles and Their Assembly into Anatase@ Titanium Oxynitride/Titanium Nitride-Graphene Nanocomposites for Rechargeable Lithium Ion Batteries with High Cycling Performance." ACS Nano 4: 6515-26.

[13] Cao, F. F., Wu, X. L., Xin, S., Guo, Y. G., and Wan, L. J. 2010. "Facile Synthesis of Mesoporous $\mathrm{TiO}_{2}-\mathrm{C}$ Nanosphere as an Improved Anode Material for Superior High Rate 1.5 V Rechargeable Li-ion Batteries Containing $\mathrm{LiFePO}_{4}$-C Cathode." J Phys Chem 114: 10308-13.

[14] Liu, S., Jia, H., Han, L., Wang, J., Gao, P., Xu, D., Yang, J., and Che, S. 2012. "Nanosheet-Constructed Porous $\mathrm{TiO}_{2}-\mathrm{B}$ for Advanced Lithium Ion Batteries." Adv Mater 24: 3201-4.

[15] Ren, Y., Liu, Z., Pourpoint, F., Armstrong, A. R., Grey, C. P., and Bruce, P. G. 2012. "Nanoparticulate $\mathrm{TiO}_{2}(\mathrm{~B}): \mathrm{An}$ Anode for Lithium-Ion Batteries." Angew Chem Int Ed 51: 2164-7.

[16] Wang, J., Zhou, Y., Hu, Y., O'Hayre, R., and Shao, Z. 2011. "Facile Synthesis of Nanocrystalline $\mathrm{TiO}_{2}$ Mesoporous Microspheres for Lithium-Ion Batteries." J Phys Chem C 115: 2529-36.

[17] Guo, W., Xue, X., Wang, S., Lin, C., and Wang, Z. L. 2012. “An Integrated Power Pack of Dye-Sensitized Solar Cell and Li Battery Based on Double-Sided $\mathrm{TiO}_{2}$ Nanotube Arrays." Nano Lett 12: 2520-3.

[18] Beranek, R., Hildebrand, H., and Schmuki, P. 2003. "Self-Organized Porous Titanium Oxide Prepared in $\mathrm{H}_{2} \mathrm{SO}_{4}$ / HF Electrolytes." Electrochem Solid-State Lett 6 : B12-B14.

[19] Liu, Y., Liu, D., Zhang, Q., and Cao, G. 2011. "Engineering Nanostructured Electrodes away from Equilibrium for Lithium-Ion Batteries." J Mater Chem 21: 
9969-83.

[20] Wang, G., Wang, H., Ling, Y., Tang, Y., Yang, X., Fitzmorris, R. C., Wang, C., Zhang, J. Z., and Li, Y. 2011. "Hydrogen-Treated $\mathrm{TiO}_{2}$ Nanowire Arrays for Photoelectrochemical Water Splitting." Nano Letters 11: 3026-33.

[21] Hu, S., Li, F., and Fan, Z. 2013. "Preparation of Dihydroxy Naphthalene $/ \mathrm{TiO}_{2}$ Complex via Surface Modification and Their Photocatalytic $\mathrm{H}_{2}$ Production Performances under Visible Light.” Bull Korean Chem Soc 34: 2056-62.

[22] Hansen, P. L., Wagner, J. B., Helveg, S., Rostrup-Nielsen, J. R., Clausen, B. S., and Topsøe, H. 2002. "Atom-Resolved Imaging of Dynamic Shape Changes in Supported Copper Nanocrystals.” Science 295: 2053-5.

[23] Jian, X., Jiang, M., Zhou, Z., Zeng, Q., Lu, J., Wang, D., Zhu, J., Gou, J., Wang, Y., Hui, D., and Yang, M. 2012. "Gas-Induced Formation of $\mathrm{Cu}$ Nanoparticle as Catalyst for High-Purity Straight and Helical Carbon Nanofibers." ACS Nano 6: 8611-9.

[24] Jian, X., Cao, Y., Chen, G., Wang, C., Tang, H., Yin, L., Luan, C., Liang, Y., Jiang, J., Wu, S., Zeng, Q., Wang, F., and Zhang, C. 2014. "High-purity $\mathrm{Cu}$ Nanocrystal Synthesis by a Dynamic Decomposition Method." Nanoscale Res Lett 9: 1-9.

[25] Lin, J., Lin, Y., Liu, P., Meziani, M. J., Allard, L. F., and Sun, Y. P. 2002. "Hot-Fluid Annealing for Crystalline Titanium Dioxide Nanoparticles in Stable Suspension." JACS 124: 11514-8.

[26] Rai, A. K., Anh, L. T., Gim, J., Mathew, V., Kang, J., Paul, B. J., Song, J., and Kim, J. 2013. "Simple Synthesis and Particle Size Effects of $\mathrm{TiO}_{2}$ Nanoparticle Anodes for Rechargeable Lithium Ion Batteries.” Electrochim Acta 90: $112-8$.

[27] Liu, N., Schneider, C., Freitag, D., Hartmann, M., Venkatesan, U., Müller, J., Spiecker, E., and Schmuki, P. 2014. "Black $\mathrm{TiO}_{2}$ Nanotubes: Cocatalyst-Free Open-Circuit Hydrogen Generation." Nano Letters 14: 3309-13.

[28] Liu, D., Xiao, P., Zhang, Y., Garcia, B. B., Zhang, Q., Guo, Q., Champion, R., and Cao, G. 2008. " $\mathrm{TiO}_{2}$ Nanotube Arrays Annealed in $\mathrm{N}_{2}$ for Efficient Lithium-Ion Intercalation." J Phys Chem C 112: 11175-80.

[29] Liu, D., Zhang, Y., Xiao, P., Garcia, B. B., Zhang, Q., Zhou, X., Jeong, Y. H., and Cao, G. 2009. "TiO2 Nanotube Arrays Annealed in CO Exhibiting High Performance for Lithium Ion Intercalation.” Electrochim Acta 54: 6816-20.

[30] Wagemaker, M., Borghols, W. J. H., and Mulder, F. M. 2007. "Large Impact of Particle Size on Insertion Reactions. A Case for Anatase $\mathrm{LixTiO}_{2}$." JACS 129: 4323-7.

[31] Hu, Y. S., Kienle, L., Guo, Y. G., and Maier, J. 2006.
"High Lithium Electroactivity of Nanometer-Sized Rutile $\mathrm{TiO}_{2}$." Adv Mater 18: 1421-6.

[32] Deshpande, S., Patil, S., Kuchibhatla, S. V., and Seal, S. 2005. "Size Dependency Variation in Lattice Parameter and Valency States in Nanocrystalline Cerium Oxide." Appl Phys Lett 87: 133113.

[33] Anwar, T., Wang, L., Liang, T., He, X., Sagar, R. U. R., and Shehzad, K. 2015. "Effect of Aspect Ratio of Titanium Dioxide Nanotube Arrays on the Performance of Lithium Ion Battery." Int J Electrochem Sc 10: 6537-47.

[34] Anwar, T., Wang, L., Jiaoyang, L., Chen, W., Sagar, R. U. R., and Tongxiang, L. 2016. "Lithium Storage Study on $\mathrm{MoO}_{3}$-Grafted $\mathrm{TiO}_{2}$ Nanotube Arrays." Appl. Nanosci.: 1-9.

[35] Lu, Z., Yip, C. T., Wang, L., Huang, H., and Zhou, L. 2012. "Hydrogenated $\mathrm{TiO}_{2}$ Nanotube Arrays as High-Rate Anodes for Lithium-Ion Microbatteries." ChemPlusChem 77: 991-1000.

[36] Jiang, W. T., Peacor, D. R., ÁRkai, P., TÓTh, M., and Kim, J. W. 1997. "TEM and XRD Determination of Crystallite Size and Lattice Strain as a Function of Illite Crystallinity in Pelitic Rocks." J METAMORPH GEOL 15: 267-81.

[37] Kubiak, P., Fröschl, T., Hüsing, N., Hörmann, U., Kaiser, U., Schiller, R., Weiss, C. K., Landfester, K., and Wohlfahrt-Mehrens, M. 2011. "TiO2 Anatase Nanoparticle Networks: Synthesis, Structure, and Electrochemical Performance." Small 7: 1690-6.

[38] Ortiz, G. F., Hanzu, I., Knauth, P., Lavela, P., Tirado, J. L., and Djenizian, T. 2009. " $\mathrm{TiO}_{2}$ Nanotubes Manufactured by Anodization of Ti Thin Films for On-chip Li-Ion 2D Microbatteries." Electrochimica Acta 54: 4262-8.

[39] Kavan, L., Gratzel, M., Gilbert, S. E., Klemenz, C., and Scheel, H. J. 1996. "Electrochemical and Photoelectrochemical Investigation of Single-Crystal Anatase." JACS 118: 6716-23.

[40] Liu, D., Xiao, P., Zhang, Y., Garcia, B. B., Zhang, Q., Guo, Q., Champion, R., and Cao, G. 2008. " $\mathrm{TiO}_{2}$ Nanotube Arrays Annealed in $\mathrm{N}_{2}$ for Efficient Lithium-Ion Intercalation." J Phys Chem C 112: 11175-80.

[41] Anji Reddy, M., Pralong, V., Varadaraju, U. V., and Raveau, B. 2008. "Crystallite Size Constraints on Lithium Insertion into Brookite $\mathrm{TiO}_{2}$." Electrochem Solid-State Lett 11: A132-A134.

[42] Shah, N. A., Sagar, R. R., Mahmood, W., and Syed, W. A. A. 2012. "Cu-doping Effects on the Physical Properties of Cadmium Sulfide Thin Films." J Alloy Compd 512: 185-9.

[43] Ahmad, M. I., and Bhattacharya, S. S. 2009. "Size Effect on the Lattice Parameters of Nanocrystalline Anatase." Appl Phys Lett 95: 191906.

[44] Hosseinpour, P. M., Panaitescu, E., Heiman, D., Menon, L., and Lewis, L. H. 2013. "Toward Tailored Functionality 
Effect of Annealing Atmosphere Induced Crystallite Size Changes on the Electrochemical Properties of $\mathrm{TiO}_{2}$ Nanotubes Arrays

of Titania Nanotube Arrays: Interpretation of the Magnetic-Structural Correlations." Journal of Materials Research 28: 1304-10.

[45] Pegah, M. H., Daniel, Y., Eugen, P., Don, H., Latika, M.,
David, B., and Laura, H. L. 2014. "Correlation of Lattice Defects and Thermal Processing in Thecrystallization of Titania Nanotube Arrays." Materials Research Express 1: 045018. 